e-ISSN: 2359-5078

\title{
Comportamento de algumas indústrias de alimentos no Brasil sobre fatores que influenciam a inovação de produtos
}

Behavior of some food industries in Brazil on factors that influence product innovation

\author{
Rosileide Siqueira Ferreira ${ }^{1}$; Ana Ligia Giraldeli ${ }^{*}$
}

${ }^{1}$ PECEGE, MBA em Gestão de Projetos - Avenida Pádua Dias, Bairro Agronomia - 13418-900 - Piracicaba, SP - Brasil.

${ }^{2 *}$ ESALQ/USP - Doutoranda em Fitotecnia - Av. Pádua Dias, 11 - Departamento de Produção Vegetal - 13418-900 - Piracicaba, SP - Brasil< analigia_giraldeli@hotmail.com>

\section{Resumo}

A indústria de alimentos tem grande importância na economia do país. As empresas precisam estar sempre buscando por inovação, tanto de produtos como de processos. Esta pesquisa teve como objetivo principal, obter através da ótica dos profissionais atuantes na indústria de alimentos no Brasil, dados referentes ao comportamento destas empresas, que possam ser considerados fatores críticos de influência ao processo de inovação de produto que pudessem vir a justificar o baixo nível de inovatividade dentro deste setor, que muito embora seja, altamente competitivo ainda possui grande campo de oportunidade a ser explorado no que tange a inovação de produto. Para tal foi elaborado um questionário online, pelo qual, a partir de sua devolutiva, foi possível identificar que por mais que haja apoio da alta direção nas empresas pesquisadas, em sua maioria empresa de médio a grande porte e em alguns casos um ambiente criativo, ainda são necessárias algumas mudanças de comportamento para alcançar maiores e melhores resultados com inovação de produtos. Podemos citar como exemplo o alinhamento de comunicação, integração e engajamento entre as diversas áreas, melhor provisão e gerenciamento de recursos tanto interno quanto externos. Também se busca por pessoal qualificado, recursos financeiros e planejamento de custo e prazo, além da necessidade de melhorar a mensuração dos resultados de inovação com metas não apenas para medir a eficácia das inovações, como também para desencadear melhorias dentro dos processos pelos quais as inovações são geradas e executadas.

Palavras-chave: estratégia, indústria alimentícia, pesquisa e desenvolvimento de produto, planejamento

\begin{abstract}
The food industry has great importance in the country's economy. Companies need to be always looking for innovation, both products and processes. This research had as main objective, to obtain from the perspective of the professionals working in the food industry in Brazil, data concerning the behavior of these companies, which can be considered critical factors of influence to the process of product innovation that could justify the low level of innovation within this sector, which although highly competitive, still has a great field of opportunity to be explored regarding product innovation. For that, an online questionnaire was drawn up, through which, from its devolutive point of view, it was possible to identify that, although there is support from top management in the companies surveyed, mostly medium to large companies and in some cases a creative, some behavioral changes are still needed to achieve greater and better results with product innovation. We can cite as an example the alignment of communication, integration and engagement among the different areas, better provision and management of resources both internal and external. It also seeks qualified personnel, financial resources and cost and time planning, as well as the need to improve the measurement of innovation results with goals not only to measure the effectiveness of innovations but also to trigger improvements within the processes by which innovations are generated and executed.
\end{abstract}

Keywords: strategy, food industry, product research and development, planning

\section{Introdução}

Inovar é a peça fundamental para o crescimento em um ambiente competitivo. Sem inovação, a organização fica estagnada e, consequentemente, os concorrentes assumem a liderança e a empresa acaba morrendo (Davila et al., 2007). A inovação caracteriza-se como a descoberta, a busca, experimentação e desenvolvimento de novos produtos, processos e pela melhoria da gestão organizacional. É um procedimento interativo, em que existe a participação tanto de agentes econômicos como sociais, incluindo diferentes tipos de informações e conhecimentos que obrigatoriamente possuem uma relação direta com os agentes regionais (Jacoski et al., 2014).

A indústria de alimentos foi uma das principais responsáveis pelo primeiro surto industrial no Brasil ocorrido ao final do século XIX após a primeira guerra 
mundial. A produção de alimentos foi a segunda maior atividade industrial no Brasil, com uma representatividade de mais de $20 \%$ do valor total da produção industrial, sendo superada apenas pela produção têxtil (Suzigan, 2012).

Ainda hoje a indústria de alimentos desempenha um papel fundamental na economia do país, sendo possível sustentar esta afirmação, a partir dos dados do balanço econômico do ano de 2016, que apresenta um faturamento nominal do setor de transformação de alimentos e bebidas de $\mathrm{R} \$ 614,3$ bilhões, o setor conta com 32,5 mil empresas, é também o setor que mais emprega com 1,6 milhão de funcionários (ABIA, 2016).

A participação do setor de alimentos e bebidas no saldo da balança comercial brasileira é de alto peso. Em 2016, o setor contribuiu com saldo de US $\$ 31,5$ bilhões para o superávit total da balança comercial do país, que foi de US\$ 47,7 bilhões (ABIA, 2016). Um setor de tamanha importância como este merece atenção ao que se refere a inovação de seus produtos, pois o mercado alimentício é extremamente dinâmico e cada vez mais exigente, novos nichos e tendências de mercado têm surgido ano após ano, mudanças quanto às necessidades dos consumidores e a forma de consumo destes, o que gera uma pressão contínua por mudanças dentro das indústrias alimentícias.

Por esse motivo, as empresas devem estar atentas ao movimento da concorrência, e as mudanças no contexto no qual estão inseridas e se for o caso substituir produtos antigos ou obsoletos, diversificar o portfólio de produtos oferecidos e melhorar constantemente o desempenho destes. Para isso, devem desenvolver novas tecnologias ou melhorar e adaptar, de maneira criativa, tecnologias existentes às necessidades de produção da empresa. Contudo é fundamental compreender que inovação não deve ser tratada como um evento e sim como um processo que precisa ser gerenciado e bem planejado, para que possa ser bem-sucedido (Tidd et al., 2005).

No Brasil, o principal instrumento de medição do nível de inovação nas empresas é a Pesquisa de Inovação [PINTEC], realizada pelo Instituto Brasileiro de Geografia e Estatística [IBGE]. Para que seus resultados possam servir de base comparativa com outros países a PINTEC baseia-se no Manual de Oslo versão 2004.

Indicadores fornecidos pela última versão da PINTEC divulgada em 2014, nos permitem afirmar que das empresas fabricantes de alimentos que implementaram inovações, apenas 55\% destas inovaram em produtos, enquanto que $88 \%$ inovaram em processo.

A partir destas considerações, foi motivado o direcionamento deste trabalho, no sentido de obter informações através da ótica dos profissionais atuantes na indústria de alimentos no Brasil de como as empresas têm se comportado com relação a alguns potenciais fatores que influenciam as inovações em produtos.
O resultado deste estudo pode oferecer aos gestores das indústrias de alimentos no Brasil, uma visão sobre quais fatores podem ser observados com mais atenção no planejamento e execução no processo de inovação de produtos, contribuindo assim na assertividade em futuros projetos.

\section{Material e Métodos}

A primeira etapa deste estudo foi a realização do levantamento de dados secundários a partir do último relatório divulgado pelo IBGE da PINTEC de 2014, que além de divulgar os dados de nível de inovação nas empresas nacionais pesquisadas, também apresentou os principais problemas e obstáculos para a realização de inovação, chamados aqui de fatores, que foram tomados como ponto de partida para a segunda etapa deste trabalho, uma pesquisa quantitativa descritiva (PINTEC, 2016).

A pesquisa buscou apurar opiniões de diversos profissionais atuantes na indústria de alimentos no Brasil, a amostra utilizada foi por conveniência, e a participação na pesquisa foi voluntária e não identificada (Hair et al., 2005).

Optou-se por uma pesquisa do tipo "survey", elaborado por um questionário online através na plataforma online, este instrumento de coleta de dados possuía característica descritiva, pois pretendia descrever fatos e fenômenos da realidade com enfoque quantitativo.

O questionário continha 26 itens, sendo duas perguntas de controle, a primeira identificando o setor de atividade da empresa a qual o respondente fazia parte, pois o foco da pesquisa eram as empresas alimentícias, portanto qualquer respondente de outro ramo de atividade foi excluído da pesquisa. A segunda pergunta de controle questionou se a empresa realizava projetos de inovação e desenvolvimento de produto, se esta resposta foi negativa, este respondente também foi excluído da amostra a ser analisada.

A partir dessas respostas haviam sete questões fechadas, com intuído de caracterizar a amostra: identificação do perfil dos respondentes, tamanho da empresa, se esta possui uma área de Pesquisa e Desenvolvimento [P\&D], o que caracteriza como uma empresa que possui em sua rotina as atividades relacionas a inovações de produtos, assim como o departamento de atuação do respondente, bem como sua formação acadêmica, gênero e faixa etária.

Nos demais itens do questionário foram feitas 17 afirmações relacionadas a fatores preponderantes para a realização de inovação de produto, para tal, utilizou-se a escala Likert de cinco pontos, a qual, requeria aos respondentes indicarem seu grau de concordância ou discordância com às afirmações apresentadas quanto ao comportamento das empresas por eles representadas dentro da pesquisa. A cada item foi atribuída uma escala qualitativa e outra quantitativa como segue: concordo totalmente (5), concordo (4), neutro (3), discordo (2) e discordo totalmente (1) (Likert, 1932). 
Foi realizado um pré-teste, onde foram apontados pequenos problemas de interpretação e formato de algumas questões propostas. Depois de feito os ajustes, a coleta de dados seguiu normalmente.

A forma de veiculação utilizada baseou-se no envio do link para o questionário online dentro da plataforma, por e-mail para algumas empresas, sendo escolhidas de acordo com o objetivo do trabalho, fazendo parte da pesquisa as que aceitaram a participação. Via redes sociais, além de também ter sido divulgada instituição de ensino localizada na cidade de Piracicaba, estado de São Paulo. Estes meios de elaboração e veiculação da pesquisa foram elencados, em função à facilidade no preenchimento e no recebimento dos dados, além do maior anonimato dos entrevistados, permitindo maior liberdade e sinceridade nas respostas não comprometendo nem tendenciado os resultados. O questionário online ficou disponível durante 44 dias para recebimento das respostas. Mesmo sendo amplamente divulgado, a maior parte dos formulários foi respondida por pessoas do estado de São Paulo.

Para análise das respostas com base na escala Likert (Likert, 1932), primeiramente foi calculada a frequência relativa percentual de cada item da escala, concordo totalmente (5), concordo (4), neutro (3), discordo (2) e discordo totalmente (1), entretanto, foram excluídas as respostas classificadas em 3 na escala, pois é exatamente o meio da escala, significando "não concordo, nem discordo" e por isso é considerado "indiferente" ou "sem opinião", sendo o "ponto neutro" ou equivalente aos casos em que os respondentes não souberam opinar.

A frequência relativa percentual dos itens 1 e 2 foram somadas, bem como os itens 4 e 5 , dividindo a escala em dois lados, sendo, de um lado o percentual de opiniões como (discordo e discordo totalmente) e outro lado de opiniões (concordo e concordo totalmente).

Ao todo haviam 17 questões formatadas na escala Likert (Likert, 1932), que durante o tratamento das respostas foram subdivididas e relacionadas em 6 macro fatores, além daqueles identificados na Pesquisa Industrial de Inovação Tecnológica: apoio da alta direção e alinhamento à estratégia global da empresa; colaboração, comunicação e engajamento dos departamentos no processo de inovação de produto; ambiente criativo; definição de metas quanto a resultados relacionados a inovações de produtos; recursos internos (equipe qualificadas, financeiro e tempo); recursos externos (incentivos governamentais, parcerias com fornecedores, clientes e instituições de ensino).

É fundamental ressaltar que não foram coletadas apenas respostas de profissionais que atuam diretamente na área de P\&D, devido à grande importância que as demais áreas possuem dentro do processo de desenvolvimento de produto, cada qual tendo sob sua responsabilidade atividades cruciais para o sucesso durante o processo de inovação de produtos, visto se tratar de um processo multidisciplinar.
Portanto, as opiniões e percepções de profissionais de outros departamentos na indústria de alimentos foram muito importantes para a geração de informações dentro deste trabalho, que enriqueceu a pesquisa e poderá ser observado no próximo tópico.

\section{Resultados e Discussão}

A inovação é o processo que inclui as atividades técnicas, a concepção, o desenvolvimento e a gestão, o que resulta na comercialização de novos (ou melhorados) produtos ou na utilização de novos (ou melhorados) processos. Assim, diferentemente de invenções, que se limitam à criação de um processo, uma técnica ou um produto, a inovação é a introdução da invenção no mercado de algo novo ou aprimorado.

Schumpeter (1939) classificou em cinco categorias as inovações: novos produtos, novos métodos de produção, novos mercados, novas fontes de matériaprima e novas formas de organização. Contudo, a maior parte dos estudos empíricos focam as inovações de produto e processo, consideradas mais fáceis de serem mensuradas. Neste estudo, apenas a inovação de produto foi pesquisada.

A inovação de produtos não somente trata $\mathrm{O}$ desenvolvimento de produtos inéditos, mas também o melhoramento significativo de produtos já existentes. Os produtos novos são caracterizados por sua diferenciação no que diz respeito aos atributos tecnológicos ou quanto seu uso pretendido diferencia-se dos produtos previamente produtos. Enquanto a inovação de processo compreende o aprimoramento ou desenvolvimento de novos meios de produção, distribuição de bens ou formas de prestação de serviços. As mudanças podem ser compreendidas não somente via aquisição de equipamentos novos, mas também pela exploração de novos métodos de produção, aperfeiçoamento de formas de distribuição e diferentes meio de prestação de serviço (Mattos, 2008).

Os esforços de inovação podem ser do tipo incremental ou radical. As inovações do tipo incremental são aquelas que buscam pequenas melhorias nos produtos e processos de produção existentes. As mudanças de design que um modelo de automóvel pode apresentar de um ano para outro representam uma inovação do tipo incremental de produto, que, obviamente, gera mudanças nos processos de produção. Além de serem menos custosas, geralmente possuem comportamento mais imediatista, com menor risco envolvido, e propiciam maiores benefícios no curto prazo (Jugend e Silva, 2013).

A inovação radical é aquela que apresenta características sem precedentes e promove melhorias significativas de desempenho ou de custo, alterando os mercados existentes ou abrindo novas possibilidades e fronteiras de mercado (Leifer et al., 2002). 
Destaca-se aqui duas principais formas de inovar dentro da indústria: Inovar em produto e inovar em processo. Onde em ambas as formas a inovação pode contribuir de diversas maneiras. Pesquisas indicam, por exemplo, que há uma forte relação entre o desempenho do mercado e novos produtos, onde estes podem ser fundamentais para a conquista e ou a manutenção de fatias de mercado, bem como aumentar a lucratividade neste mercado. No caso de produtos já estabelecidos no atual portfólio, o aumento de vendas pode vir não apenas da capacidade de oferecê-los a baixos preços, porém pode-se agregar fatores como design, customização e qualidade de produto ou serviço.

No atual cenário mundial, o ciclo de vida dos produtos tende a ser cada vez mais reduzido, a exemplo, a vida útil de um aparelho celular ou computador é medida em meses, ou ainda, produtos de composição mais complexas, como o motor de um carro, levam apenas poucos anos para ser desenvolvido, a capacidade de substituição frequente de produtos por versões mais modernas e melhoradas tem cada vez mais importância. Uma corrida contra o tempo que gera uma grande pressão sobre as empresas, que além de lançar novos produtos no mercado, precisam se atentar em fazê-lo antes que seus concorrentes o façam (Tidd e Bessant, 2015).

O desafio consiste em saber lidar com um mundo de incertezas, experimentando constantemente novas

Elevados custos da inovação

Riscos econômicos excessivos

Escassez de fontes de financiamento

Falta de pessoal qualificado

Falta de informação sobre tecnologia

Dificuldade para se adequar aos padrões

Escassas possibilidades de cooperação

Rigidez organizacional

Falta de informação sobre o mercado

Escassez de serviços técnicos

Fraca resposta dos consumidores

Centralização da atividade inovativa em outra empresa do grupo oportunidades. O sucesso no processo de inovação, parece depender de dois ingredientes principais: recursos (pessoas, equipamento, conhecimento, recursos financeiros, etc.) e capacidades das organizações para geri-los (Tidd e Bessant, 2015).

Indicadores fornecidos pela última versão da PINTEC divulgada em 2014, indicam que o percentual de dispêndio total das atividades inovativas em relação à receita líquida de vendas passou de 2,37\% em 2011 para 2,12\% em 2014, o menor patamar histórico registrado pela pesquisa, sendo que $0,87 \%$ destes foram investimentos na aquisição de máquinas e equipamentos.

Historicamente, a partir das edições anteriores da pesquisa é sabido que as inovações de processo predominam em relação às de produto, e na edição de 2014 não foi diferente. Das indústrias fabricantes de alimentos que implementaram inovações (6.168), apenas $55 \%$ destas inovaram em produtos (3.389), enquanto que $88 \%$ inovaram em processo (5.438). Partindo deste dado é possível inferir que existam maiores dificuldades na implementação de inovação de produto.

No relatório da PINTEC (2014) também foram apresentados os principais problemas e obstáculos para a realização de inovação identificados durante a pesquisa, extraindo apenas os dados da indústria que é objetivo deste trabalho, temos, por grau de importância os seguintes fatores observados na Figura 1.

\section{$86 \%$}

$82 \%$

$69 \%$

$66 \%$

$51 \%$

$44 \%$

$43 \%$

$43 \%$

$42 \%$

$42 \%$

$40 \%$

$2 \%$

Figura 1. Importância atribuída aos problemas e obstáculos para inovar pelas indústrias que implementaram inovações de produto ou processo pesquisada pela PINTEC no período 2012-2014

Fonte: adaptado de PINTEC (2014) 
Através do questionário obteve-se 162 respostas, porém somente 93 passaram pelas perguntas de controles, filtrando assim apenas as empresas do ramo alimentício (predominantemente do estado de São Paulo) que realizam projetos de inovação e desenvolvimento de produtos.

Nas questões de caracterização da amostra, foram identificadas que dos 93 respondentes, $62 \%$ (58) eram do sexo feminino e $38 \%$ (35) do sexo masculino.

No que diz respeito a faixa etária dos respondentes, houve uma predominância nas duas faixas mais jovens entre 21 e 30 anos com 48\% (39) e entre 31 e 40 anos com $38 \%$ (35), seguidas por $16 \%$ (15) entre 41 e 50 anos e 4\% (4) acima de 51 anos de idade. Não houveram respondentes abaixo de 20 anos de idade (Figura 2).

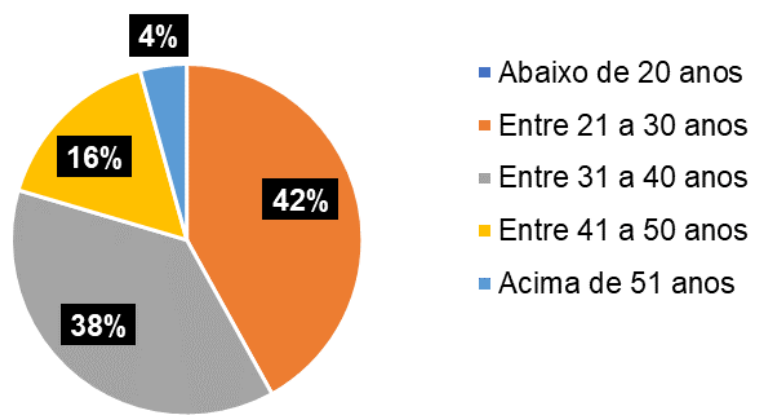

Figura 2. Faixa etária dos respondentes do questionário

Quanto a formação acadêmica dos respondentes, 54\% (50) responderam ter pós-graduação (especialização, mestrado ou doutorado), 33\% (31) o ensino superior completo, enquanto apenas 13\% (12) disseram ter o superior incompleto (Figura 3).

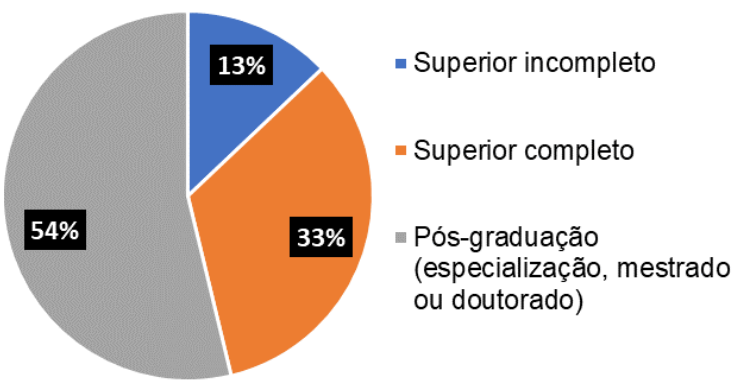

Figura 3. Formação acadêmica dos respondentes do questionário

Referente ao porte das empresas das quais os respondentes faziam parte, foram obtidas as seguintes respostas: $56 \%$ (52) das empresas consideradas de grande porte tendo acima de 500 funcionários, $23 \%$ (21) das empresas consideradas de médio porte tendo entre $100 \mathrm{e}$ 499 funcionários e $22 \%$ (20) das empresas consideradas de pequeno porte com até 99 funcionários (Figura 4).

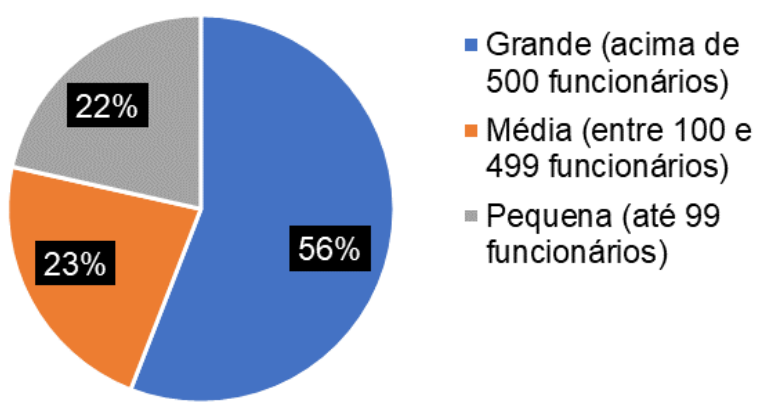

Figura 4: Porte das empresas as quais os respondentes fazem parte

Quanto a idade das empresas as quais os respondentes faziam parte, 67\% (62) estavam estabelecidas a mais de 15 anos, 13\% (12) tinham entre 0 a 5 anos, 11\% (10) de 10,1 a 15 anos e 10\% (9) de 5,1 a 10 anos (Figura 5).

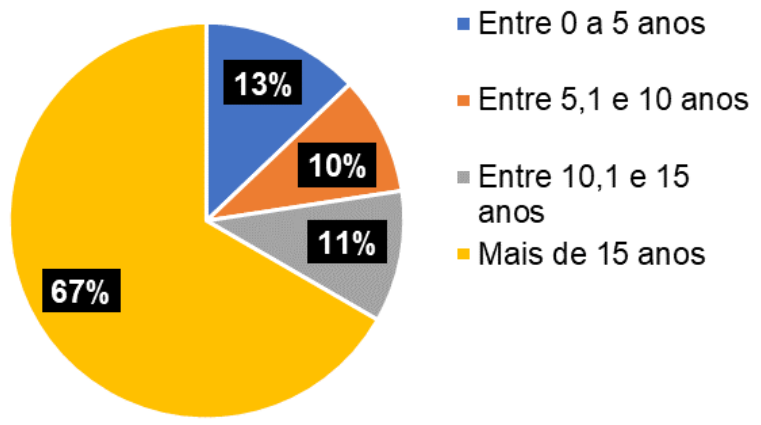

Figura 5. Idade das empresas as quais os respondentes fazem parte

Quanto à existência de um departamento de P\&D nas empresas as quais os respondentes faziam parte, 84\% (78) responderam que sim, há um departamento de P\&D nestas empresas, enquanto apenas 16\% (15) responderam que não havia.

Quando perguntado aos respondentes se estes atuavam diretamente na equipe de $\mathrm{P} \& \mathrm{D}$ de suas empresas obteve-se um número de $42 \%$ (39) de respondentes que trabalhavam na área de P\&D e 58\% (54) afirmaram fazer parte de outros departamentos como: comercial, suprimentos, consultoria, controladoria, engenharia e projetos, financeiro, logística, marketing, planejamento e controle de produção [PCP], produção, qualidade, segurança do trabalho e meio ambiente e tecnologia da informação.

Esta questão foi de grande contribuição para o enriquecimento da análise de dados, uma vez que foi possível segregar as respostas em dois grupos de respondentes, sendo o primeiro de profissionais do departamento de P\&D e, o segundo grupo de profissionais de outros departamentos, podendo ser gerado então um comparativo entre as percepções destes profissionais sobre o mesmo tema. 
Para evidenciar a importância da contribuição e envolvimento de outros departamentos além do P\&D no processo de desenvolvimento de produtos, é possível visualizar na Tabela 1 um breve resumo das principais atividades que competem a estes outros departamentos com relação direta com o processo de desenvolvimento de novos produtos.

Tabela 1. Atividades gerais dos departamentos envolvidos com o Processo de Desenvolvimento de Produtos [PDP]

\begin{tabular}{|c|c|}
\hline Função/Departamento & Atividades gerais \\
\hline Marketing & $\begin{array}{l}\text { Abastecer o PDP de informações sobre o mercado, sendo fundamental tanto para as } \\
\text { decisões sobre desenvolver um novo produto e suas características como para colocar o } \\
\text { produto desenvolvido no mercado e coletar informações sobre ele. }\end{array}$ \\
\hline Vendas & $\begin{array}{l}\text { Muitas vezes a área de vendas é subordinada à gerência de marketing. Por ser o elo direto } \\
\text { entre cliente e empresa, pode captar valiosas informações, tais como necessidades de } \\
\text { clientes, características dos produtos e oportunidades para o desenvolvimento de novos } \\
\text { produtos. }\end{array}$ \\
\hline Engenharia & $\begin{array}{l}\text { Definições, execução e melhorias do projeto do produto, do processo e preparação para a } \\
\text { produção. }\end{array}$ \\
\hline $\mathrm{P} \& \mathrm{D}$ & $\begin{array}{l}\text { Pesquisar e identificar novas tecnologias, desenvolvimento e domínio de tecnologias para } \\
\text { o projeto do produto, do processo e preparação para a produção. }\end{array}$ \\
\hline Suprimentos & $\begin{array}{l}\text { Interação com fornecedores, fornecimento de matérias-primas e componentes, } \\
\text { localização e desenvolvimento de fornecedores. }\end{array}$ \\
\hline Produção & $\begin{array}{l}\text { Elaboração do protótipo de produção, produção piloto, resolução de problemas para a } \\
\text { passagem da produção piloto à escala comercial, ações para a melhoria da capabilidade do } \\
\text { processo e reduções de custos de processamento do produto. }\end{array}$ \\
\hline Logística & $\begin{array}{l}\text { Definição de canais de distribuição e formas para a armazenagem, o manuseio e o } \\
\text { transporte do produto. }\end{array}$ \\
\hline Assistência técnica & $\begin{array}{l}\text { Os reparos e as reclamações de falhas dos produtos permitem conhecer melhor as } \\
\text { necessidades e os usos efetivos pelos clientes, conhecimento este que pode ser usado em } \\
\text { novos produtos e em melhorias nos já existentes. }\end{array}$ \\
\hline Finanças & $\begin{array}{l}\text { Cálculos de fluxos de caixa, necessidades de investimento e determinação de indicadores, } \\
\text { como taxa interna de retorno, valor presente líquido e retorno do investimento } \\
\text { e "payback", por exemplo, para o projeto do novo produto. Colaboração na definição de } \\
\text { preços e margens de contribuição de cada produto. }\end{array}$ \\
\hline Recursos humanos & $\begin{array}{l}\text { Recrutamento, seleção e desenvolvimento de profissionais para trabalhar ao longo de } \\
\text { todas as etapas do PDP. Diagnóstico de necessidade e de treinamento de pessoal para } \\
\text { trabalhar em um novo produto/serviço a ser lançado. }\end{array}$ \\
\hline Alta administração & Tomada de decisões. Planejamento estratégico. Controle de resultados. \\
\hline
\end{tabular}

Fonte: Jugend e Silva (2013)

$\mathrm{Na}$ etapa do questionário onde utilizou-se a escala Likert, foram coletadas opiniões de concordância ou discordância a respeito do comportamento das empresas as quais os respondentes faziam parte. Em relação as 17 afirmações relativas aos vários fatores e elementos que influenciam no processo de inovação de produto, estas opiniões foram subdivididas e agrupadas em seis macro fatores (Figuras 6 e 7).

Quanto à ter um apoio da alta direção e alinhamento à estratégia global da empresa quanto aos projetos de desenvolvimento de produtos, $85 \%$ dos profissionais atuantes do departamento de P\&D concordam ou concordam totalmente com esta afirmação ao passo que apenas $15 \%$ discordam ou discordam totalmente, opiniões estas, muito próximas dos demais respondentes atuantes em outros departamentos, dos quais 86\% concordam ou concordam totalmente e $14 \%$ discordam ou discordam totalmente, um sinal extremamente positivo no processos de inovação. Para alinhar a inovação com a estratégia da empresa, o peso e o tipo de inovação devem se adequar à estratégia da empresa. O uso de gestão do conhecimento possui uma relação positiva com a inovação (Alegre et al., 2011).

Há também uma percepção muito similar entre os respondentes da área de $\mathrm{P} \& \mathrm{D}$ e os demais departamentos ao afirmarem a existência de um processo colaborativo com boa interface, sinergia, comunicação e engajamento de todos os 
departamentos da empresa em se tratando do processo de inovação de produto. Entretanto dentro de ambos os grupos, opiniões bem divididas entre aqueles respondentes que concordam e discordam que há este comportamento pelas empresas nas quais fazem parte. Dentro do grupo de P\&D, 53\% concordam ou concordam totalmente, enquanto no mesmo grupo $47 \%$ discordam ou discordam totalmente, os demais departamentos são discordantes em uma porcentagem um pouco menos $43 \%$ e são concordantes em 57\%.

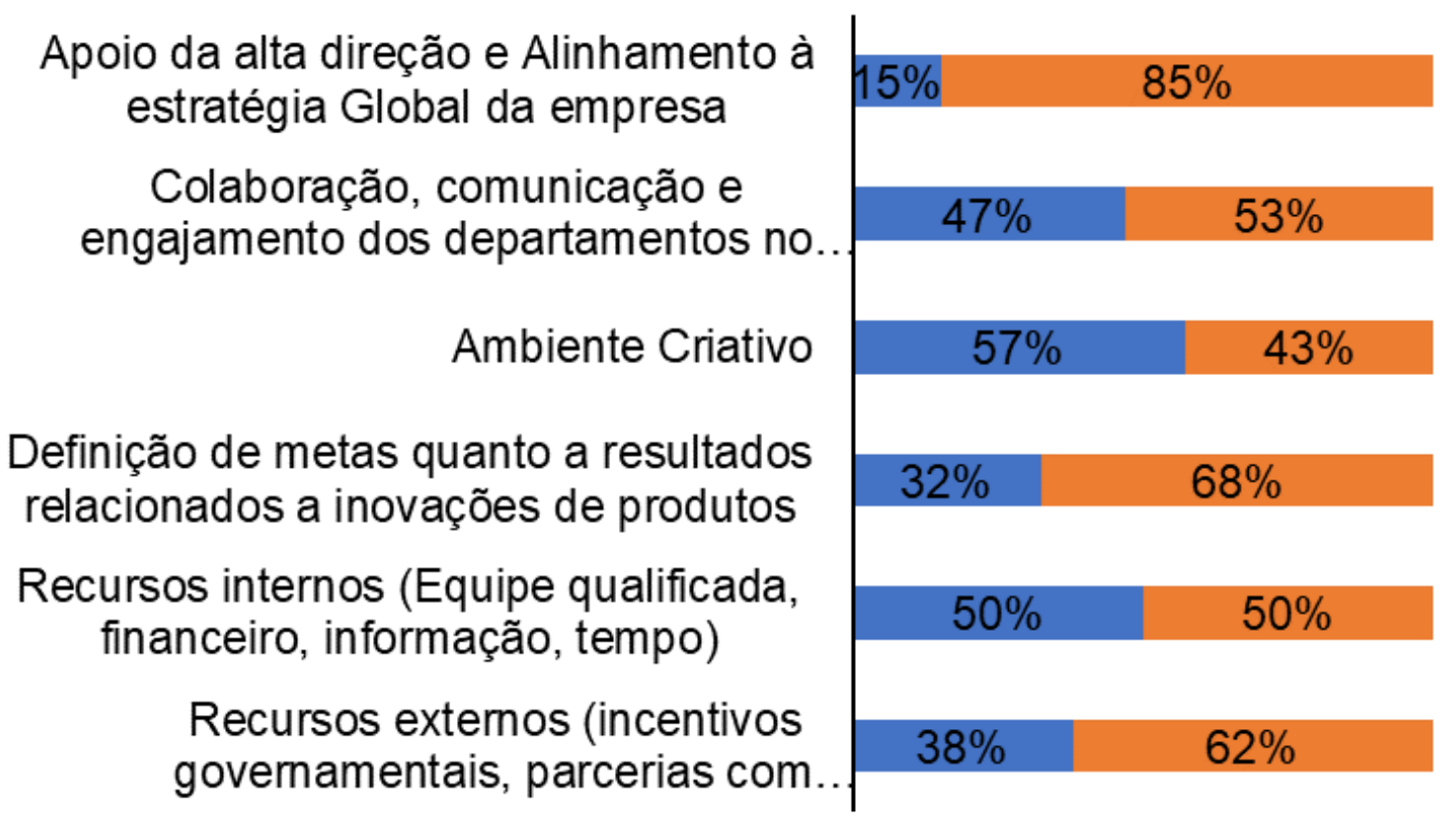

Discorda ou Discorda totalmente Concorda ou Concorda Totalmente

Figura 6. Comportamento das indústrias de alimentos quanto ao grupo de fatores pesquisados, pela ótica dos profissionais atuantes no departamento de $\mathrm{P} \& \mathrm{D}$

Apoio da alta direção e Alinhamento à estratégia Global da empresa

Colaboração, comunicação e engajamento dos departamentos no..

\section{Ambiente Criativo}

Definição de metas quanto a resultados relacionados a inovações de produtos

Recursos internos (Equipe qualificada, financeiro, informação, tempo)

Recursos externos (incentivos governamentais, parcerias com..

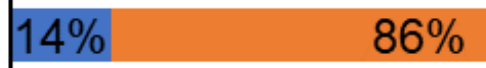
$43 \%$
$57 \%$

(1)

$40 \% \quad 60 \%$

$35 \% \quad 65 \%$

$46 \%$

$54 \%$

$40 \% \quad 60 \%$

\section{Discorda ou Discorda totalmente Concorda ou Concorda Totalmente}

Figura 7. Comportamento das indústrias de alimentos quanto ao grupo de fatores pesquisados, pela ótica dos profissionais atuantes em outros departamentos, que não o P\&D 
É possível concluir que as opiniões foram bastante divididas, evidenciando um fator preocupante, conforme Davila et al. (2007) a inovação exige recursos, competências e experiências presentes em diferentes partes das organizações, departamentos que juntos devem sincronizam e coordenar esforços, para tornar possível a transformação de ideias em produtos tangíveis que consequentemente se converterão em resultados, portanto a solidez de cooperação e colaboração interna e externa são elementos indispensáveis para a viabilizar a inovação. Segundo Pérez-López e Junquera (2013), o uso da comunicação horizontal ao invés da vertical auxilia a desenvolver o trabalho em equipe, além de estimular a troca de informações.

No que se refere a possuir um ambiente criativo, as opiniões dos dois grupos divergem significativamente, enquanto os profissionais da área de $\mathrm{P} \& \mathrm{D}$ discordam em $57 \%$ e concordam em $43 \%$, os profissionais de outros departamentos dizem discordar em $40 \%$ e concordam em $60 \%$.

O ambiente criativo é mais reconhecido pelos profissionais de outros setores enquanto que pela visão dos respondentes do setor de P\&D o comportamento das indústrias de alimentos as quais fazem parte ainda deixa a desejar neste quesito.

A criatividade tem como mecanismo gerar uma ideia, diferentemente da inovação que desenvolver aquela ideia e coloca-la no mercado (Dewes et al., 2012). O desafio real presente nessa questão é administrar a criatividade e a criação de valor lado a lado sem comprometer nenhuma delas, possibilitando a geração de grandes ideias que possam ser convertidas em sucessos comerciais.

A respeito das empresas terem metas definidas e monitoradas referentes aos resultados obtidos através da inovação de produtos, temos uma similaridade de opiniões entre os dois grupos, 68\% entre os respondentes dos departamentos de P\&D concordam e 32\% discordam desta afirmação (Figura 6), enquanto $65 \%$ dos profissionais de outros departamentos concordam e 35\% discordam (Figura 7). Através da ótica destes profissionais há ainda uma parcela significativa de empresas que não tem métodos claros para mensurar os resultados oriundos das inovações de produtos.

Vários indicadores podem servir para mensurar a inovatividade, dentre eles podem ser citados: variáveis de personalidade e comportamento comunicativo. Dentro de variáveis de personalidade está a capacidade de assumir riscos (Capitanio et al., 2010). Para conseguirem novas ideias e inovação, os líderes devem incentivar seus funcionários a assumir os riscos, ao invés de evitá-los (Ellonen et al., 2008).

Nas afirmações relativas a suficiência de recursos internos providos pela empresa para realização de inovações de produtos, como: equipe bem dimensionada para suprir as demandas de desenvolvimento de produto, equipe técnica bem qualificada, disponibilidade de recurso financeiro dentro dos projetos e tempo suficiente para execução destes, houve também uma equivalência entre as opiniões dos grupos, sendo que $50 \%$ dos respondentes dos profissionais de $\mathrm{P} \& \mathrm{D}$ discordam que há suficiência destes recursos ao passo que 50\% concordam (Figura 6), já os demais departamentos discordam em $46 \%$ e concordam em 54\% (Figura 7). A partir deste dado podese concluir que ainda há um "gap" referente à provisão de recursos internos em uma boa parcela das indústrias de alimentos para garantir a execução e sucesso nos processos de inovação de produtos.

No que diz respeito a haver uma provisão de recursos externos como incentivos financeiros governamentais, cooperação com universidade, centros de pesquisas, clientes e fornecedores, no sentido de promover informações tecnológicas que auxiliem no processo de inovações de produtos dentro das indústrias de alimentos, é possível observar que tanto pela ótica dos respondentes atuantes na área de $\mathrm{P} \& \mathrm{D}$ quanto pela ótica dos profissionais das demais áreas, que ainda há uma boa parcela de oportunidade de recursos externos a serem supridos. Dos profissionais atuantes no P\&D 38\% discordam ou discordam totalmente e $63 \%$ concordam ou concordam totalmente (Figura 6), ao passo que os demais departamentos também são discordantes em 40\% e concordante na parcela de 60\% (Figura 7).

Houve neste caso um percentual considerável de respondentes que discordam que há uma provisão de recursos externos suficiente, o que demonstra ainda uma imaturidade das empresas pesquisadas quanto a gerenciar as relações e provisão de recursos externos. Haja vista a importância deste tema, Davila et al. (2007) salientou que a mútua colaboração entre parcerias eficientes como clientes, fornecedores, consultores, pesquisadores dentre outros que possuem a capacidade de ajudar de alguma forma a empresa a se manter inovadora constitui um dos elementos centrais para gerar inovação, através destas redes que se conectam e trocam experiência e informações entre si.

As universidades, por exemplo, são parcerias potencialmente valiosas, pois constituem fontes ricas de novas tecnologias e modelos de negócios com consideráveis oportunidades de mercado, sendo uma prática comum pelas mesmas o licenciamento de novas tecnologias para as empresas.

\section{Conclusão}

É possível concluir que a inovação de produto tem sua relevância e importância reconhecida dentro das indústrias de alimentos, não apenas pelos profissionais das áreas de $\mathrm{P} \& \mathrm{D}$, mas também por outros setores incluindo a alta direção, que na maioria dos casos apoia e a tem alinhada a estratégia da empresa. 
Entretanto, nota-se ainda alguns pontos falhos no comportamento destas empresas no que tange ao gerenciamento das inovações, como o cuidado em gerar um ambiente criativo que seja notado, reconhecido e que permita a participação de todos, para que a inovação esteja inserida na rotina de trabalho de toda a empresa. Percebe-se também a falta de metas definidas e monitoradas referentes aos resultados obtidos através da inovação de produtos, ou seja, há uma parte das empresas que está deixando de mensurar os benefícios alcançados com inovação, deixando de gratificar e motivar os responsáveis pelo sucesso dos projetos, ou em caso de insucesso, estão perdendo a oportunidade de identificar e corrigir as causas deste insucesso, o que poderia para gerar a melhoria continua nos processos de inovação de produto.

No que se refere ao engajamento, comunicação e interface entre as diversas áreas das empresas, ainda há oportunidades a serem exploradas, visto que inovar requer esforços mútuos e direcionados ao mesmo foco, além de alto nível de interface entre todas as áreas da empresa, para a obtenção de sucesso com os seus resultados.

Outro ponto é a atenção que as indústrias de alimentos devem dar quanto a provisão de recursos internos e externos, como equipe bem dimensionada para suprir as demandas de desenvolvimento de produto, equipe técnica bem qualificada, disponibilidade de recurso financeiro dentro dos projetos e tempo suficiente para execução destes, além de incentivos financeiros internos ou advindos de órgão governamentais, cooperação com universidade, centros de pesquisas, clientes e fornecedores, no sentido de promover informações tecnológicas que auxiliem no processo de inovações de produtos dentro das Indústrias. Todos estes são fatores fundamentais, pois deles dependem o sucesso dos processos de inovação de produto.

Por fim, é esperado que os resultados obtidos neste estudo, possam oferecer aos gestores das indústrias de alimentos no Brasil uma visão realista sobre a percepção dos profissionais, quanto a alguns pontos importantes a serem observados no planejamento e execução no processo de inovação de produtos, contribuindo assim na assertividade em futuros projetos.

\section{Referências}

Alegre, J.;Sengupta, K.;Lapiedra, R. 2011. Knowledge management and innovation performance in a high-tech smes industry. International Small Business Journal 31: 454-470.

Associação Brasileira da Indústria de Alimentos [ABIA]. 2016. ABIA divulga balanço do setor de alimentos e bebidas. Disponível em: <http://www.abia.org.br/vsn/tmp_2. aspx?id=319\#sthash.8nKsNEgY.OEsia0Ni.dpbs $>$. Acesso em: 17 jul. 2017.
Capitanio, F.; Coppola, A.; Pascucci, S. 2010. Product and process innovation in the italian food industry. Agribusiness 26: 503-518.

Davila, T.; Epstein, M.J.; Shelton, R. 2007. As regras da inovação. Editora Bookman, Porto Alegre, RS, Brasil.

Dewes, F.; Neves, F.M.; Jung, C.F.; Caten, C.S. 2012. Ambientes e estímulos favoráveis à criatividade aplicada a processos de inovação de produtos. Revista Venezolana de Gestión Tecnológica (Espacios) 38: 1-16.

Ellonen, R.; Blomqvist, K.; Puumalainen, K. 2008. The role of trust in organizational Innovativeness. European Journal of Innovation Management 11: 160-181.

Hair, J.; Babin, B.; Money, A.; Samouel, P. 2005. Fundamentos de métodos de pesquisa em administração. Editora Bookman, Porto Alegre, RS, Brasil.

Jacoski, C.A.; Dallacorte, C.; Bieger, B.N.; Deimling, M.F. 2014. Análise do desempenho da inovação regional: um estudo de caso na indústria. Revista de Administração e Inovação 11: 71-88.

Jugend, D.; Silva, S.L. 2013. Inovação e desenvolvimento de produtos: práticas de gestão e casos brasileiros. Grupo GenLTC.

Leifer, R.; O’Connor, G.C.; Rice, M. 2002. A implementação de inovação radical em empresas maduras. Revista de Administração de Empresas 42: 17-30.

Likert, R. 1932. A technique for the measurement of attitudes. Archives of psychology 22: 55 .

Mattos, J.R.L. 2008. Gestão da tecnologia e inovação. Editora Saraiva, São Paulo, SP, Brasil.

Manual, D.O. 2004. Proposta de diretrizes para coleta e interpretação de dados sobre inovação tecnológica. OCDE. Organização para Cooperação e Desenvolvimento Econômico: Departamento Estatístico da Comunidade Europeia. Disponível em: <http://www.finep.gov.br/ images/a-finep/biblioteca/manual_de_oslo.pdf $>$. Acesso em: 24 jun. 2017.

Pérez-López, S.; Junquera, B. 2013. The relation between it competency and knowledge management processes and its mediators. Tourism \& Management Studies 9: 109115.

Pesquisa de Inovação [PINTEC]. 2014. Disponível em: <http://www.pintec.ibge.gov.br> Acesso em: 15 jul. 2017.

Pesquisa de inovação [PINTEC]. 2016. IBGE, Coordenação de Indústria. IBGE, Rio de Janeiro, RJ, Brasil.

Schumpeter, J.A. 1939. Business cycles: a theoretical, historical, and statistical analysis of the capitalist process. McGraw-Hill. Disponível em: <http://docenti.lett.unisi.it/ files/115/17/2/1/BusinessCycles_Fels.pdf $>$. Acesso em: 17 jul. 2017.

Suzigan, W. 2012. Industrialização brasileira em perspectiva histórica. História Econômica \& História de Empresas 3: 7-25.

Tidd, J.; Bessant, J. 2015. Gestão da inovação. Editora Bookman, São Paulo, SP, Brasil.

Tidd, J.; Bessant, J.; Pavitt, K. 2005. Managing innovation: integrating technological, market and organizational change. West Sussex: John Wiley \& Sons. 